\title{
Leakage Rate After Laparoscopic Sleeve Gastrectomy; How Much Affected by Staple-line Reinforcement?
}

\author{
Ahmed Talha MD, MRCS; ${ }^{1}$ Khaled Katri MD, FRCS. ${ }^{2}$
}

\author{
1) Department of Surgery, Medical Research Institute, Alexandria University, Egypt. \\ 2) Department of Surgery, Faculty of Medicine, Alexandria University, Egypt.
}

Background: LSG is an easy and safe technique with a shorter learning curve. The risk of staple-line bleeding, leakage, and dehiscence are much higher because of long staple-line. This study was carried out to detect the importance of staple-line reinforcement.

Methods: Between April 2010 and September 2013, 166 consecutive patients with a diagnosis of morbid obesity based on the guidelines issued by IFSO who underwent LSG and completed their follow-up for a minimum one year were classified into; (group A) 84 patients with and (group B) 82 patients without staple-line reinforcement at Alexandria University. Outcome parameters including; leakage, bleeding, operative time, surgical complications, hospital stay, and follow-up details, were collected.

Results: The demographic parameters were comparable in the two groups. No conversion to open surgery was detected. There was insignificant leakage rate as $2(2.4 \%)$ cases were found in group $B$ and none in group $A(P=0.86)$. There was insignificant difference between both groups as regard bleeding from staple-line, short gastric vessels or splenic tear. No stenosis was found in either group. The mean operative time in group A (99.7 \pm 19.1 minutes) was significantly longer than in group $B(76.3 \pm 9.5$ minutes $)(P=0.015)$. Hospital stay was significantly prolonged in group $B(2.5 \pm 4.9$ days) than group $A(1.95 \pm 0.4$ days) $(P=0.031)$. No significant difference was found regarding the other outcome parameters.

Conclusions: LSG is an effective and safe bariatric procedure with low incidence of complications and mortality in our experience. Reinforcement of the staple-line did not have any additional benefit, although a larger study is required to reach a definitive conclusion.

Key words: Laparoscopic sleeve gastrectomy, obesity, reinforcement, staple-line leakage.

\section{Introduction:}

Laparoscopic sleeve gastrectomy (LSG) has been considered to be the first of a twostage procedure in high-risk patients. ${ }^{1,2}$ It had been reported to be an effective, safer, and time-saving independent procedure for the treatment of morbid obesity with acceptable percentage of excess weight loss $\left(\%\right.$ EWL). ${ }^{3,4}$ The lack of implanted nonabsorbable material, the retention of normal gastrointestinal (GI) continuity, the avoidance of malabsorption, and convertibility to other operations makes LSG a more widely used bariatric procedure.5,6,7 Although long-term results are still pending, early outcomes reported in the literature for treatment of morbid obesity and type 2 diabetes with LSG are very encouraging. Although sleeve gastrectomy initially was considered a purely restrictive procedure, recent studies have shown that it may function through other mechanisms such as decreasing the satiety hormone; ghrelin. 8,9

In comparison to gastric bypass surgery, LSG is an easier and safer technique with a shorter learning curve. Leakage was the most common and most dreaded complication after the LSG because of the extra-long stapleline retained, and it may lead to abdominal sepsis, abscess formation, chronic fistula, multiorgan failure, and death. There has been no standardized procedure for preventing 
leakage, and there is no consensus regarding the different techniques in LSG. ${ }^{10}$

The risk of staple-line bleeding, staple-line leaks, and dehiscence are much higher because of long staple-line. Attempts to optimize the staple line have included oversewing it with suture, covering it with omentum or jejunum, and reinforcing it with an array of materials. Surgeons are divided between those who reinforcewith buttress material, those who oversaw and those who don't do either. Materials used for reinforcement have expanded to polytetrafluoroethylene (ePTFE; W. L. Gore \& Associates Inc., Flagstaff, AZ, USA), bovine pericardium (BPS; Peri-Strips Dry, Synovis, St. Paul, MN, USA), small intestinal submucosa (Surgisis; Cook, Inc., Bloomington, IN, USA), and the bioabsorbable polyglycolide acid and trimethylene carbonate (SeamGuard, W.L. Gore \& Associates, Inc.). ${ }^{11-14}$

This debate about the importance of staple-line reinforcement has motivated us to conduct our present study aiming to detect the impact of staple-line reinforcement in LSG on leakage and other complications rate.

\section{Study design:}

This is a prospective randomized controlled trial. The design involved 166 patients with a diagnosis of morbid obesity based on the guidelines issued by the International Federation for Surgery of Obesity (IFSO) ${ }^{15}$ to undergo LSG at the Department of Surgery, Medical Research Institute Hospital and the Main University Hospital, Alexandria University, between April 2010 and September 2013.

Patients were considered eligible after evaluation of clinical history, a thorough physical examination, blood chemistry and hormonal status. They were divided into two groups: Group A (LSG with reinforcement of staple-line) and group B (LSG without reinforcement of staple-line). Outcome parameters including; leakage, bleeding, operative time, surgical complications, hospital stay, and follow-up details, were collected.

\section{Eligibility:}

Inclusion criteria:

History of obesity $>5$ years, failure of conservative weight loss treatment (at least 6 months), BMI $>40 \mathrm{~kg} / \mathrm{m}^{2}$ or $>35 \mathrm{~kg} / \mathrm{m}^{2}$ with co-morbidities and age between 18 and 60 years.

Exclusion criteria:

Contraindications to creation of pneumoperiteoneum (e.g. Glaucoma), American Society of Anesthesiologists (ASA) class IV and V, large esophageal hiatal hernias $(>3 \mathrm{~cm})$, severe esophagitis, pregnancy, drug or alcohol abuse, psychological disorders (e.g. Bulimia, depression), hormonal or genetic obesity-related disease, previous gastric surgery or refusal.

\section{Ethics:}

A specific informed consent form approved by our Institution's Ethics Committee was signed by all candidates and was required before surgery including thorough information about the risks of the surgery, the expected weight loss, and the effects on eating habits.

\section{End points:}

Primary endpoint: To evaluate theincidence of postoperative complications in the two groups of patients. Major complications were defined as leakage (chronic fistula formation, abscess accumulation, leakage found in upper gastrointestinal image study), hemorrhage (postoperative blood transfusion), stenosis, gastrostasis, and cardiopulmonary complications. Minor complication (was defined as wound bleeding or wound infection.)

Secondary endpoints: (1) Perioperative parameters (operative time, intraoperative technical considerations, and surgical complications, (2) Operative blood loss, (4) Hospital stay, and (5) Follow-up details [weight, BMI, \%EWL, resolution of comorbidities, and postoperative investigations]. 


\section{Randomization:}

Eligible patients were randomized into two groups; Group A (LSG with reinforcement of staple-line) and group B (LSG without reinforcement of staple-line) using sealed opaque envelopes containing computer-generated random numbers. The randomization was performed 1 week before surgery during the preoperative assessment.

\section{Surgical technique:}

All procedures were performed with the patient placed in a split leg position with the knees slightly flexed and hip externally rotated. Surgery was performed in a steep reverse Trendelenburg position. Patient preparation included nasogastric tube, urine catheter, and customized compression stockings. All pressure points were cushioned. Pneumoperiteoneum was created using the Veress needle technique or using a visual port; Excel $^{\mathrm{TM}}$ (Ethicon Endosurgery, Cincinnati, $\mathrm{OH}$, USA). Five ports used. Using the xiphisternum as an anatomical landmark, an arc is made at $18 \mathrm{~cm}$, with ports to the left and right mid-clavicular lines (Operating ports), and left of midline (camera port). The liver was retracted using a liver retractor via an epigastric (sub-xiphisternal) port. Last port at left anterior axillary line for retraction.

The surgery began by the division of the gastrocolic omentum begin six cm proximal to the pylorus (identified by "crow's foot") using the Harmonic Scalpel ${ }^{\mathrm{TM}}$ (Ethicon Endosurgery, Cincinnati, OH, USA) and proceeds up to the angle of His. The short gastric vessels were identified and divided. Dissection was performed up to the left crus of the hiatus, and all attachments were released to completely mobilize the fundus.

The gastric sleeve was created using sequential firings of a $60-\mathrm{mm}$ linear stapling device (Echelon ${ }^{\mathrm{TM}}$ 60; Endopath ${ }^{\circledR}$ Stapler, Ethicon Endosurgery, Cincinnati, OH, USA). The stapler was applied alongside a 38-Fr calibrating bougie positioned against the lesser curve so as to avoid stenosis and to obtain a narrow gastric tube.

Care was always taken during the stapling not to crumble the stomach inside the stapler by avoiding caudal traction of the stomach. This was particularly important at the region of the fundus of the stomach. It was also of importance to avoid the crossing over of the staples, which could cause the stapler's knife disturbing the junction between the consecutive firings. This was achieved by applying the stapler to the middle of preceding end of the staple line.

The bougie was withdrawn, and in group $\mathrm{B}$, the staple-line was reinforced using continuous seromuscular invaginating sutures, $2-3 \mathrm{~mm}$ lateral to the staple line. The sutures covered the staple-line from the esophagogastric junction until approximately the level of the gastric incisura, using polypropylene $3 / 0,26-30-\mathrm{mm}$ round needle (Ethicon Sutures, Cincinnati, Ohaio, USA) in a continuous manner.

A leak test was performed using intraoperative diluted methylene blue dye. The resected specimen was retrieved via the $15-\mathrm{mm}$ port. A drain was placed, hemostasis was ensured, and port sites were closed.

\section{Postoperative course:}

Ambulation was encouraged, and chest physiotherapy was started in the immediate postoperative period. An upper gastrointestinal contrast study using watersoluble contrast (Gastrograffin) was done on the first postoperative day. Clear liquids were started on confirmation of staple-line integrity. The patient was discharged once oral intake of 1,500-2,000 $\mathrm{ml} / 24 \mathrm{~h}$ was established. Prokinetics, and proton pump inhibitors (PPIs) were continued for ten days. All medications were given orally in crushed or liquid form. The drain was removed on the second postoperative day. A liquid diet was given for two weeks, a pureed/soft diet for six weeks, and normal diet thereafter. Dietary counseling was provided, and a normal consistency, low-calorie, high protein diet is advised at two months from surgery. Patients with an intact gall bladder were prescribed Ursodeoxycholic acid $(600 \mathrm{mg} / \mathrm{d})$ for six months as gallstone prophylaxis. 


\section{Follow-up:}

Patients were followed up at 1, 3, 6, and 12 postoperative months and then annually.

\section{Statistical considerations:}

A personal PC with SPSS version 20.0 was used for analysis. Significant level was set at alpha $=(0.05)$. Descriptive statistics included: Arithmetic mean, standard deviation and median. Kolmogrov-Smirnov test for testing normal distribution was used to test the distribution of data which did not follow normal distribution thus were analyzed using Mann-Whitney test for comparing 2 independent groups. Chi- square test $\left(\chi^{2}\right)$ was used to test the association between two categorical variables and to detect difference between proportions.

\section{Results:}

166 patients who had LSG were included in the study. 52(31.3\%) patients were males and $114(68.7 \%)$ were females. Mean age was $31.2 \pm 8.6$ years, mean preoperative BMI was $49 \pm 6.5 \mathrm{~kg} / \mathrm{m}^{2}$ and Excess weight was $64.9 \pm 23.2 \mathrm{~kg}$ in group A and $65.3 \pm 23.6 \mathrm{~kg}$ in group B. Onset of obesity started at adulthood in $45(27.1 \%)$ patients, at childhood in $83(50 \%)$ patients and at puberty in $38(22.9 \%)$ patients. Characteristics of patients among the studied groups were similar. There was no significant difference between the two groups in all these demographic data Table (1).

Duration of the procedure was significantly prolonged in reinforcement group where it was $99.7 \pm 19.1$ minutes in group A and $76.3 \pm 9.5$ minutes in group B Table (2).

Bleeding from short gastric vessels was reported in eight cases; 3 (3.6\%) in groupA and $5(6 \%)$ in group $B$ which was controllable with either clipping or vessel coagulation using Harmonic Scalpel ${ }^{\mathrm{TM}}$ (Ethicon Endosurgery, Cincinnati, OH, USA) with no need for blood transfusion with insignificant statistical difference between them Table (2).

Also, bleeding from staple-line was reported in $4(4.8 \%)$ cases in group A and in $6(7.3 \%)$ cases in group B which was controlled conservatively by applying clips over the bleeding points and mostly occurred near pylorus with insignificant difference between them Table (2).

Two cases of splenic injury in form of laceration while dissecting the short gastric at gastric fundus; one in either group which was controlled by compression using a piece of gauze with no significant difference between them Table (2).

Two cases of gastric leakage were recorded in group B and neither in group A. One case was reported on second postoperative day from esophagogastric junction which was managed using self-expandable fully covered esophageal metallic stent (after failure of conservative treatment for 10 days) under endoscopic and fluoroscopic guidance with successful closure of the fistulous tract after 25 days and stent was removed after 7 weeks. Drain was kept in place until no discharge and confirmed by $\mathrm{CT}$ with oral gastrograffin. While, the other case, leakage was detected after four days and the patient was managed conservatively on total parenteral nutrition (TPN), PPIs and antibiotic cover plus CT guided drainage catheter was inserted to drain the left subphrenic collection. Complete healing of fistulous tract was achieved after 20 days with negative drain output which was confirmed by CT with oral gastrograffin followed by drain removal. The diagnosis of leak in the last two patients was achieved by CT scan, which was requested upon clinical suspicion.

Duration of drain removal was $2.19 \pm 1.54$ days in group A and $2.4 \pm 2.0$ days in group $B$ with insignificant difference between them. Hospital stay was significantly shorter in group A than in group B where it was $1.95 \pm 0.4$ days in group A and $2.5 \pm 4.9$ days in group B (Table II) due to prolonged stay of leakage cases in group B as the first patient with leakage stayed for 45 days while the other one stayed for one month as they had chest infection.

There was no significant difference between both groups as regard \%EWL at one year Table (2). Also, there was no significant difference between both groups regarding the postoperative follow-up laboratory investigations at 1, 3, 6 and 12 months. 
Table (1): Preoperative Patient Demographic data.

\begin{tabular}{|c|c|c|c|c|c|c|c|c|c|c|}
\hline & \multicolumn{6}{|c|}{ Group } & & & & \multirow{3}{*}{ P-value } \\
\hline & \multicolumn{3}{|c|}{ Group "A" } & \multicolumn{3}{|c|}{ Group "B" } & \multicolumn{3}{|c|}{ Total } & \\
\hline & \multicolumn{2}{|c|}{ No. $(n=84)$} & $\%$ & \multicolumn{2}{|c|}{ No. $(n=82)$} & $\%$ & \multicolumn{2}{|c|}{ No. $(n=166)$} & $\%$ & \\
\hline \multicolumn{10}{|l|}{ Gender } & \multirow[t]{3}{*}{0.265} \\
\hline Male & \multicolumn{2}{|l|}{26} & 31.0 & \multicolumn{2}{|l|}{26} & 31.7 & \multicolumn{2}{|l|}{52} & 31.3 & \\
\hline Female & \multicolumn{2}{|l|}{58} & 69.0 & \multicolumn{2}{|l|}{56} & 68.3 & \multicolumn{2}{|l|}{114} & 68.7 & \\
\hline $\begin{array}{l}\text { Onset of } \\
\text { obesity }\end{array}$ & & & & & & & & & & \multirow[t]{4}{*}{0.442} \\
\hline Adult & \multicolumn{2}{|l|}{23} & 27.4 & \multicolumn{2}{|l|}{22} & 26.8 & \multicolumn{2}{|l|}{45} & 27.1 & \\
\hline Child & \multicolumn{2}{|l|}{41} & 48.8 & \multicolumn{2}{|l|}{42} & 51.2 & \multicolumn{2}{|l|}{83} & 50.0 & \\
\hline Puberty & \multicolumn{2}{|l|}{20} & 23.8 & \multicolumn{2}{|l|}{18} & 22.0 & \multicolumn{2}{|l|}{38} & 22.9 & \\
\hline & Mean & SD & Median & Mean & SD & Median & Mean & SD & Median & \\
\hline Age & 32.8 & 9.5 & 32.0 & 30.3 & 7.9 & 30.0 & 31.2 & 8.6 & 31.0 & 0.365 \\
\hline Weight $(\mathrm{Kg})$ & 135.0 & 24.1 & 130.5 & 138.9 & 26.7 & 139.5 & 136.8 & 25.9 & 134.0 & 0.452 \\
\hline Height(cm) & 166.7 & 14.4 & 163 & 166.9 & 14.5 & 165 & 166.8 & 14.6 & 164 & 0.521 \\
\hline BMI & 48.9 & 6.6 & 48 & 49.1 & 6.4 & 47.9 & 49.0 & 6.5 & 47.9 & 0.265 \\
\hline Ideal Wt & 70.5 & 13.9 & 66.4 & 70.4 & 14.4 & 68.0 & 70.4 & 13.9 & 67.0 & 0.33 \\
\hline Excess Wt & 64.9 & 23.2 & 62.3 & 65.3 & 23.6 & 64.0 & 65.1 & 23.4 & 63.2 & 0.46 \\
\hline
\end{tabular}

$\mathrm{Wt}=$ weight $(\mathrm{Kg})$

$\mathrm{BMI}=$ Body Mass Index $(\mathrm{kg} / \mathrm{m} 2)$

Table (2): Operative and postoperative parameters.

\begin{tabular}{|c|c|c|c|}
\hline & \multicolumn{2}{|c|}{ Group } & \multirow{2}{*}{ P-value } \\
\hline & Group "A" "n=84" & Group "B" " $\mathrm{n}=82$ " & \\
\hline Duration of procedure(min) & $\begin{array}{l}99.7 \pm 19.1 \\
100\end{array}$ & $\begin{array}{l}76.3 \pm 9.5 \\
75.0\end{array}$ & $0.015^{*}$ \\
\hline \multicolumn{4}{|l|}{ Complications } \\
\hline Staple-line bleeding & $4(4.8 \%)$ & $6(7.3 \%)$ & 0.425 \\
\hline Short gastric bleeding & $3(3.6 \%)$ & $5(6 \%)$ & 0.365 \\
\hline Splenic injury & $1(1.2 \%)$ & $1(1.2)$ & 1.0 \\
\hline Leakage & $0(0 \%)$ & $2(2.4 \%)$ & 0.86 \\
\hline Stenosis & $0(0 \%)$ & $0(0 \%)$ & - \\
\hline Duration of drain(days) & $\begin{array}{l}2.19 \pm 1.54 \\
2.0\end{array}$ & $\begin{array}{l}2.4 \pm 2.0 \\
2.0\end{array}$ & 0.103 \\
\hline Hospital stay(days) & $\begin{array}{l}1.95 \pm 0.4 \\
2.0\end{array}$ & $\begin{array}{l}2.5 \pm 4.9 \\
2.0\end{array}$ & $0.031 *$ \\
\hline \% EWL(at 6 months) & $\begin{array}{l}46.83 \pm 70.02 \\
18.18\end{array}$ & $\begin{array}{l}39.63 \pm 44.5 \\
18.9\end{array}$ & 0.107 \\
\hline
\end{tabular}

$\%$ EWL: Percentage of excess weight loss

There was a significant resolution of preoperative comorbidities in either group compare to their follow-up at three, six and twelve months with no significant difference between the two groups. There was no significant difference between the two groups 
regarding minor complication in terms of wound bleeding or wound infection. No stenosis nor mortality were found in either group.

\section{Discussion:}

Sleeve gastrectomy is widely accepted worldwide as a primary operation for obese patients and offers certain advantages compared to other well established bariatric procedures as lack of an intestinal anastomosis, normal intestinal absorption, no risk of internal hernias, no implantation of a foreign body, pylorus preservation with no dumping syndrome, and maintenance of gastrointestinal continuity with the possibility to explore the entire gastrointestinal tract. ${ }^{16}$ The weight loss after LSG is achieved due to two mechanisms of restriction and hormonal modulation. ${ }^{17-18}$

The most frequent and troublesome complications after LSG are postoperative bleeding and leakage which increase the morbidity and hospital stay ${ }^{19-21}$ and accounts for $1-3 \%$ in large published series ${ }^{22-26}$ and are the most frequent causes of death after bariatric surgery. ${ }^{27}$

The exact explanation of staple-line leaks after LSG is unclear. It could result from compromise of blood supply especially, at the angle of His near the crura, stapler device failure, poor technique, and postoperative gastroparesis with an intact pylorus causing increase in intragastric pressure. ${ }^{28-29}$ Hence, the belief that staple-line reinforcement which is a matter of surgeon preference should increase its strength and helps to decrease the incidence of staple-line complications, however, many surgeons still believe that the previously mentioned pathophysiologic factors can't be overcome with reinforcement of staple-line. ${ }^{29}$

Ser et $\mathrm{al}^{30}$ in their experience in 118 consecutive patients, found a significant leakage rate between reinforcement or no reinforcement, reporting a $0 \%$ leak rate in the reinforced group versus $10 \%$ in the nonreinforced group, which is one of the greatest published differences.

While, our results showed, two cases of leakage $(2.4 \%)$ in the non-reinforced group and none $(0 \%)$ in reinforced group which is a statistically insignificant difference between the two groups and no mortality in either group which is in accordance with published series. $^{22-26}$

Dapri et $\mathrm{al}^{31}$ who showed, through a prospective randomized trial, comparing non-reinforcement, suture reinforcement, and stapler-load buttressing, a difference in intraoperative blood loss parameters, but, no difference for leak rate, after staple-line reinforcement. They did not report any deaths in their study, and their overall leak rate was $4 \%$ to $6 \%$ also, there was an additional cost and time of staple-line reinforcement may be justified by reduced intraoperative bleeding complications. However, in our study, there was insignificant intraoperative bleeding from short gastric vessels, staple-line or splenic laceration which is statistically insignificant difference between the two studied groups also, no deaths were found in our study.

The same results obtained by Musella et $\mathrm{al}^{20}$ in their study with 100 cases, showed no significant difference in the rate of leak or bleeding but, reported a higher rate of stenosis with staple-line reinforcement and this could be attributed to some technical points, such as the type of cartridge load and bougie size. In contrast to our results, we did not experience any case of stenosis in reinforcement group that could be explained by standardization of our technique.

In the current study, we avoided many potential confounders by standardizing many variables that could affect the results. Starting with choice of the patients, patient demographic data, anesthetic regimen, $38 \mathrm{Fr}$ bougie, Echelon ${ }^{\mathrm{TM}} 60$ (Endopath ${ }^{\circledR}$ Stapler, Ethicon Endosurgery, Cincinnati, OH, USA) was used for closing. First two ignitions were started with golden cartridges then, proceeded with blue cartridge. Start of stapling $6 \mathrm{~cm}$ from pylorus till angle of Hiss, and having the same postoperative and follow-up regimens.

Currently, there is no consensus on how to manage the staple-line to prevent hemorrhage and leak. According to Rubin et $\mathrm{al},{ }^{32}$ LSGs was done for 120 patients without 
reinforcement with no postoperative leak, hemorrhage or stricture. While, Kasalicky et al[33], in their series of 61 patients without buttressing of the staple line also had a zero leak rate, but in their last 24 cases were covered with SurgicelTM (Johnson and Johnson, Langhorne, PA) strips, which were however placed without any fixation to the underlying gastric tissue.

This is in contrast to Choi et al, ${ }^{34}$ who reported through a meta-analysis of 8 studies that staple-line reinforcement had the advantages of decreased postoperative leak and overall complications. This may very well because of the differences in study design (systematic review versus meta-analysis) and, therefore, types of articles included in the analysis.

However, in a retrospective study conducted by Simon et al, 35 they reported that the usage of Seamguard decreases stapleline leakage and bleeding. Also, in another study $^{21}$ in which Seamguard and PDS 2.0 sutures were used, there was no significant difference between the two techniques. In accordance to Chen et al, 36 they have demonstrated that staple-line reinforcement does not lead to significant decrease in staple line leakage rates.

Bülbüller et al, ${ }^{37}$ compared three different methods of reinforcement using continuous serosal 3/0 prolene sutures, v-loc suture and Tisseel fibrin sealant applied throughout the staple line versus no reinforcement demonstrating that good results can be obtained without any reinforcement. Reinforcement with propylene suture only prolongs the operation time, tissue fibrin sealent increases the cost and careful using of v-loc sutures. However, their study was of 65 patients only, included in the four groups.

Our results suggest that LSG is a safe bariatric technique and the crucial point might be the technique rather than the stapleline reinforcement.

\section{Conclusion:}

LSG is an effective and safe bariatric procedure with low incidence of complications and mortality. Reinforcement of the staple-line did not have any additional benefit, however, future larger studies are required to reach a definitive conclusion on leak rates and overall morbidity in LSG.

Conflict of interest: There is no conflict of interest or financial ties to include.

\section{Reference:}

1- Lagacé M, Marceau P, Marceau S, Hould FS, Potvin M, Bourque RA, Biron S: Biliopancreatic diversion with a new type of gastrectomy. Obes Surg 1993; 3: 29-35.

2- Ren CJ, Patterson E, Gagner M: Early results of biliopancreatic diversion with duodenal switch: A case series of 40 consecutive patients. Obes Surg 2000; 10: 514-523.

3- Fuks D, Verhaeghe P, Brehant O: Results of laparoscopic sleeve gastrectomy: A prospective study in 135 patients with morbid obesity. Surgery 2009; 145(1): 106-113.

4- Arias E, Mart1'nez PR, Ka Ming Li V, Szomstein S, Rosenthal RJ: Mid-term follow-up after sleeve gastrectomy as a final approach for morbid obesity. Obes Surg 2009; 19(5): 544-548.

5- Frezza EE: Laparoscopic vertical sleeve gastrectomy for morbid obesity. The future procedure of choice? Surg Today 2007; 37: 275-281.

6- Gumbs AA, Gagner M, Dakin G, et al: Sleeve gastrectomy for morbid obesity. Obes Surg 2007; 17: 962-969.

7- Chen B, Kiriakopoulos A, Tsakayannis D, Wachtel MS, Linos D, Frezza E: Reinforcement does not necessarily reduce the rate of staple line leaks after sleeve gastrectomy. A Review of the literature and clinical experiences. Obes Surg 2009; 19: 166-172.

8- Langer FB, Reza Hoda MA, Bohdjalian A, Felberbauer FX, Zacherl J, Wenzl E, Schindler K, Luger A, Ludvik B, Prager G: Sleeve gastrectomy and gastric banding: Effects on plasma ghrelin levels. Obes Surg 2005; 15: 1024-1029.

9- Ariyasu H, Takaya K, Tagami T, Ogawa Y, Hosoda K, Akamizu T, Suda M, Koh T, Natsui K, Toyooka S, Shirakami G, Usui T, Shimatsu A, Doi K, Hosoda H, Kojima M, Kangawa K, Nakao K: Stomach is a major source of circulating ghrelin, and feeding state determines plasma ghrelin-like immunoreactivity levels in humans. J Clin Endocrinol Metab 2001; 86: 4753-4758.

10- Ser KH, Lee WJ, Lee YC, Chen JC, Su YH, 
Chen SC: Experience in laparoscopic sleeve gastrectomy for morbidly obese Taiwanese: Staple-line reinforcement is important for preventing leakage. Surg Endosc 2010; 24(9): 2253-2259.

11- Nguyen NT, Longoria M, Chalifoux S, et al: Bioabsorbable staple-line reinforcement for laparoscopic gastrointestinal surgery. Surg Technol Int 2005; 14: 107-111.

12- Arnold W, Shikora SA: A comparison of burst pressure between buttressed versus nonbuttressed staple-lines in an animal model. Obes Surg 2005; 15: 164-171.

13- Downey DM, Harre JG, Dolan JP. Increased burst pressure in gastrointestinal staple-line using reinforcement with a bioprosthetic material. Obes Surg 2005; 15: 1379-1383.

14- Franklin ME Jr, Ramila GP, Treviño JM, et al: The use of bioabsorbable staple-line reinforcement for circular stapler (BSG "SeamGuard") in colorectal surgery: Initial experience. Surg Laparosc Endosc Percutan Tech 2006; 16: 411-415.

15- International Federation for the Surgery of Obesity: Statement on patient selection for bariatricsurgery. Obes Surg 1997; 7: 41.

16- Gentileschi P: Laparoscopic sleeve gastrectomy as a primary operation for morbid obesity: Experience with 200 Patients. Gastroenterology Research and Practice 2012; Article ID 801325, 4 pages doi:10.1155/2012/801325.

17- Clinical Issues Committee of the American Society for Metabolic and Bariatric Surgery: Updated position statement on sleeve gastrectomy as a bariatric procedure. Surg Obes Relat Dis 2010; 1: 1-5.

18- Nocca D: Laparoscopic adjustable gastric banding and laparoscopic sleeve gastrectomy: Which has a place in the treatment of diabetes in morbidly obese patients? Diabetes Metab 2009; 35: 524-527.

19- Sakran N, Goitein D, Raziel A, Keidar A, Beglaibter N, Grinbaum R, et al: Gastric leaks after sleeve gastrectomy: A multicenter experience with 2,834 patients. Surg Endosc 2013; 27: 240-545.

20- Musella M, Milone M, Bellini M, Leongito M, Guarino R, Milone F: Laparoscopic sleeve gastrectomy. Do we need to oversew the staple line? Ann Ital Chir 2011; 82: 273-277.

21- Albanopoulos K, Alevizos L, Flessas J, Menenakos E, Stamou KM, Papailiou J, et al: Reinforcing the staple line during laparoscopic sleeve gastrectomy: Prospective randomized clinical study comparing two different techniques. Preliminary results. Obes Surg 2012; 22: 42-46.

22- Bellanger DE, Greenway FL: Laparoscopic sleeve gastrectomy, 529 cases without a leak: Short-term results and technical considerations. Obes Surg 2011; 21: 146-150.

23- Rice RD, Simon TE, Seery JM, Frizzi JD, Husain FA, Choi YU: Laparoscopic sleeve gastrectomy: Outcomes at a military training center. Am Surg 2010; 8: 835- 840.

24- Menenakos E, Stamou KM, Albanopoulos $\mathrm{K}$, et al: Laparoscopic sleeve gastrectomy performed with intent to treat morbid obesity: A prospective single-center study of 261 patients with a median follow-up of 1 year. Obes Surg 2010; 3: 276-82.

25- Basso N, Casella G, Rizzello M, et al: Laparoscopic sleeve gastrectomy as first stage or definitive intent in 300 consecutive cases. Surg Endosc 2011; 2: 444-449.

26- Gadiot RP, Biter LU, Zengerink HJ, et al: Laparoscopic sleevegastrectomy with an extensive posterior mobilization: Technique and preliminary results. Obes Sur 2012; 2: 320-329.

27- Daskalakis M, Berdan Y, Theodoridou $\mathrm{S}$, Weigand $\mathrm{G}$, Weiner RA: Impact of surgeon experience and buttress materialon postoperative complications after laparoscopic sleeve gastrectomy. Surg Endosc 2011; 1: 88-97.

28- Knapps J, Ghanem M, Clements J, Merchant AM: A systematic review of staple-line reinforcement in laparoscopic sleeve gastrectomy. JSLS 2013; 17: 390-399.

29- Chen B, Kiriakopoulos A, Tsakayannis D, et al: Reinforcementdoes not necessarily reduce the rate of staple line leaksafter sleeve gastrectomy. A review of the literature and clinicalexperiences. Obes Surg 2009; 19: 166-172.

30- Ser KH, Lee WJ, Lee YC, Chen JC, Su YH, Chen SC: Experience inlaparoscopic sleeve gastrectomy for morbidly obese Taiwanese: Staple- line reinforcement is important for preventing leakage. Surg Endosc 2010; 9: 2253-2259.

31- Dapri G, Cadiere GB, Himpens J: Reinforcing the staple-lineduring laparoscopic sleeve gastrectomy: Prospective randomized clinical study comparing three different techniques. Obes Surg 2010; 4: 462-467.

32- Rubin M, Yehoshua RT, Stein M, et al: Laparoscopic sleeve gastrectomy with minimal morbidity. Early results in 120 morbidly obese patients. Obes Surg 2008; 
18(12): 1567-1570.

33- Kasalicky M, Michalsky D, Housova J, et al: Laparoscopic sleeve gastrectomy without an over-sewing of the staple line. Obes Surg 2008; 18(10): 1257-1262.

34- Choi YY, Bae J, Hur KY, Choi D, Kim YJ: Reinforcing the staple-line during laparoscopic sleeve gastrectomy: Does it have advantages? A meta-analysis. Obes Surg 2012; 22: 1206-13.

35- Simon TE, Scott JA, Brockmeyer JR, Rice RC, Frizzi JD, Husain FA, Choi YU: Comparison of staple-line leakage and hemorrhage in patients undergoing laparoscopic sleeve gastrectomy with or without Seamguard. Am
Surg 2011; 77: 1665-1668.

36- Chen B, Kiriakopoulos A, Tsakayannis D, Wach $\neg$ tel MS, Linos D, Frezza EE: Reinforcement does not necessarily reduce the rate of staple line leaks after sleeve gastrectomy. A review of the literature and clinical experiences. Obes Surg 2009; 19: 166-172.

37- Bülbüller N, Aslaner A, Öner OZ, Oruç MT, Koç Ü, Öngen NA, Eryılmaz R, Cantilav G, Habibi M, Özdemir S: Comparison of four different methods in staple line reinforcement during laparascopic sleeve gastrectomy. Int $J$ Clin Exp Med 2013; 6(10): 985-990. 